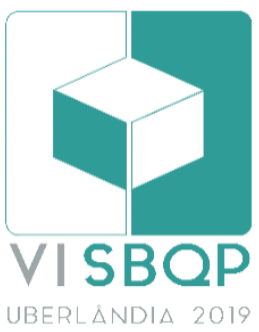

\title{
PLANO POLÍTICO EM LOTEAMENTOS DE PATROCÍNIO PAULISTA E OS IMPACTOS RELACIONADOS AO MEIO AMBIENTE
}

\author{
BETETTE, Beatriz Santos Silva \\ Universidade Federal de Uberlândia (UFU), e-mail: beatrizbetette@gmail.com \\ LOPES, Jaqueline Santos Silva \\ Universidade Federal do Mato Grosso (UFMT), e-mail: jaquee-santosss@hotmail.com \\ DAMIS VITAL, Giovanna Teixeira \\ Universidade Federal de Uberlândia (UFU), e-mail: giovannadamis@ufu.br
}

\begin{abstract}
RESUMO
Trata-se de uma pesquisa de campo, originada através de participação em estágio de campo no setor de Arquitetura, Urbanismo e Meio Ambiente da prefeitura do município de Patrocínio Paulista - SP. O artigo tem como objetivo apresentar o plano político de parcelamento do solo e loteamento urbano recente, vigente no município de Patrocínio Paulista, demonstrar os avanços efetuados em áreas rurais e seus respectivos impactos ambientais e sociais. Essa cidade, de pequeno porte, localiza-se no interior do Estado de São Paulo e se desenvolveu a partir de descobertas de diamantes nos ribeirões da região, fator primordial a urbanização local. Atualmente, o cenário é marcado por loteamento de propriedades anteriormente rurais, os quais culminaram em crescente urbanização seguida da ausência de planejamento urbano estruturante às questões ambientais. Para o desenvolvimento do estudo, foi utilizada metodologia de análise comparativa do desenho urbano do município em um intervalo de 15 anos - 2003 a 2018, a fim de analisar a distribuição da malha urbana de loteamento no solo e o cumprimento das exigências da Lei Federal №6.766. Para isso, foram utilizadas ferramentas computacionais georreferenciadas e documentos históricos arquivados em regime da Prefeitura Municipal de Patrocínio Paulista. O presente trabalho constitui ferramenta importante na identificação e sugestão de estratégias que impeçam a degradação ambiental e promovam a recuperação da paisagem. Assim, proporciona conservação de patrimônio paisagístico local e possibilita novas perspectivas para os habitantes, além de traduzir o enfoque social ao plano construtivo e compreender o projeto urbano e a qualidade ambiental como intrínsecos.
\end{abstract}

Palavras-chave: Infraestrutura Verde, Preservação Ambiental, Planejamento Ambiental, Plano Diretor.

\begin{abstract}
It is a field research, originated through participation in a field internship in the Architecture, Urbanism and Environment sector of the municipality of Patrocínio Paulista - SP. The article aims to present the political plan for land parceling and recent urban development in the municipality of Patrocínio Paulista, to demonstrate the advances made in rural areas and their respective environmental and social impacts. This small city is located in the interior of the state of São Paulo and developed from diamond discoveries in the region's rivers, a key factor in local urbanization. Currently, the scenario is marked by the subdivision of previously rural properties, which culminated in increasing urbanization followed by the absence of urban planning structuring environmental issues. For the development of the study, a methodology of comparative analysis of the urban design of the municipality was used in an interval of 15 years - 2003 to 2018 , in order to analyze the distribution of the urban mesh of allotment in the soil and the fulfillment of the requirements of the Federal Law No6 .766. For this, we used georeferenced computational tools and historical documents filed under the auspices of the Municipal Government of Patrocínio Paulista. The present work constitutes an important tool in the identification and suggestion of strategies that prevent environmental degradation and promote the recovery of the landscape. Thus, it provides conservation of local landscape patrimony and allows new perspectives for the
\end{abstract}

BETETTE, B. S. S.; LOPES, J. S. S.; DAMIS VITAL, G. T. Plano políitico em loteamentos de Patrocínio Paulista e os impactos relacionados ao meio ambiente. In: SIMPÓSIO BRASILEIRO DE QUALIDADE DO PROJETO NO AMBIENTE CONSTRUÍDO, 6., 2019, Uberlândia. Anais... Uberlândia: PPGAU/FAUED/UFU, 2019. p. 495-501. DOI https://doi.org/10.14393/sbqp19046. 
inhabitants, besides translating the social approach to the constructive plane and understanding urban design and environmental quality as intrinsic.

Keywords: Green Infrastructure, Environmental Preservation, Environmental Planning, Master Plan.

\section{INTRODUÇÃO}

O município em questão, teve gênese na atividade garimpeira praticada na região sudeste do país. Habitada inicialmente por índios Caiapós, Patrocínio Paulista emplacou início ao seu processo de urbanização a partir de 1830, ano em que foi descoberta a existência de diamante na região. Também, tal fato foi marcado por atrair garimpeiros de toda parte do país em busca de riquezas. Atribuindo, portanto, o subnome "Terra do Diamante", Patrocínio Paulista tornou-se vila e emancipou-se no ano de 1885 (FÉLIX, 2012).

Localizada à nordeste do Estado de São Paulo, a aproximadamente 413 quilômetros da capital, é vista como ponto intermediário no trânsito São PauloMinas Gerais, próxima a cidades notáveis e de influência regional, como Franca, Ribeirão Preto e Uberaba. Empresas de destaque econômico do município, são voltadas a produção agrícola, suplementação animal e pecuária leiteira, setores estes, que movimentam a economia local. Produções de Iaranja, milho, soja e apicultura são setores de menor produção, também desenvolvidos no município.

Segundo O IBGE (2010), a cidade registrou uma população de 13.000 habitantes, sendo 10.499 residentes na área urbana; e 2.501 na área rural, ocupando um território de 602,848 quilômetros quadrados. A área rural conta com 14 bairros, sendo eles: São Tomé, Cachoeira, Antas, Chagas, Palmital, Lambari, Lopes, Taquaral, Campo Limpo, Humaitá, Barranco Alto, Bebedouro, Santa llda e Potreiro. Nos últimos anos, é notável o passo a que a área urbana avança sobre a área rural, por meio de loteamentos residenciais. Desde 2003, dez novos loteamentos foram regularizados e executados, sendo um deles, um condomínio horizontal, e outras duas extensões de bairros já existentes (ver Figura 1).

A partir da Lei Federal $N^{\circ}$ 6.766, ficam estabelecidas diretrizes e deveres a serem considerados na elaboração de loteamentos, ou qualquer espécie de parcelamento do solo urbano, respeitando a legislação e a vertente ambiental, no contexto do ambiente construído. Embora leis federais serem regidas em território nacional, as leis e decretos municipais podem contrastar no que é descrito na Legislação Brasileira. Dessa forma, muitos elementos observados na Lei №6.766 não se concretizam na prática de loteamentos no município em questão, refletindo nos moldes da prática construtiva urbana em conjuntura pública municipal. Neste cenário, é necessário enfatizar o não cumprimento da norma legislativa na elaboração de lotes, uma vez que seu descumprimento reflete na qualidade urbana e do indivíduo, além de ferir a diretriz ambiental. Fato que coloca em pauta a necessidade de projetar para o indivíduo residente no município tratado, sendo colocado em primeiro plano, e não, em último, como é visto. A partir do exposto, o presente trabalho teve por objetivo apresentar o plano político de parcelamento do solo e verificar a consonância com normas políticas implementadas em loteamentos recentes do município e os respectivos impactos ambientais. 


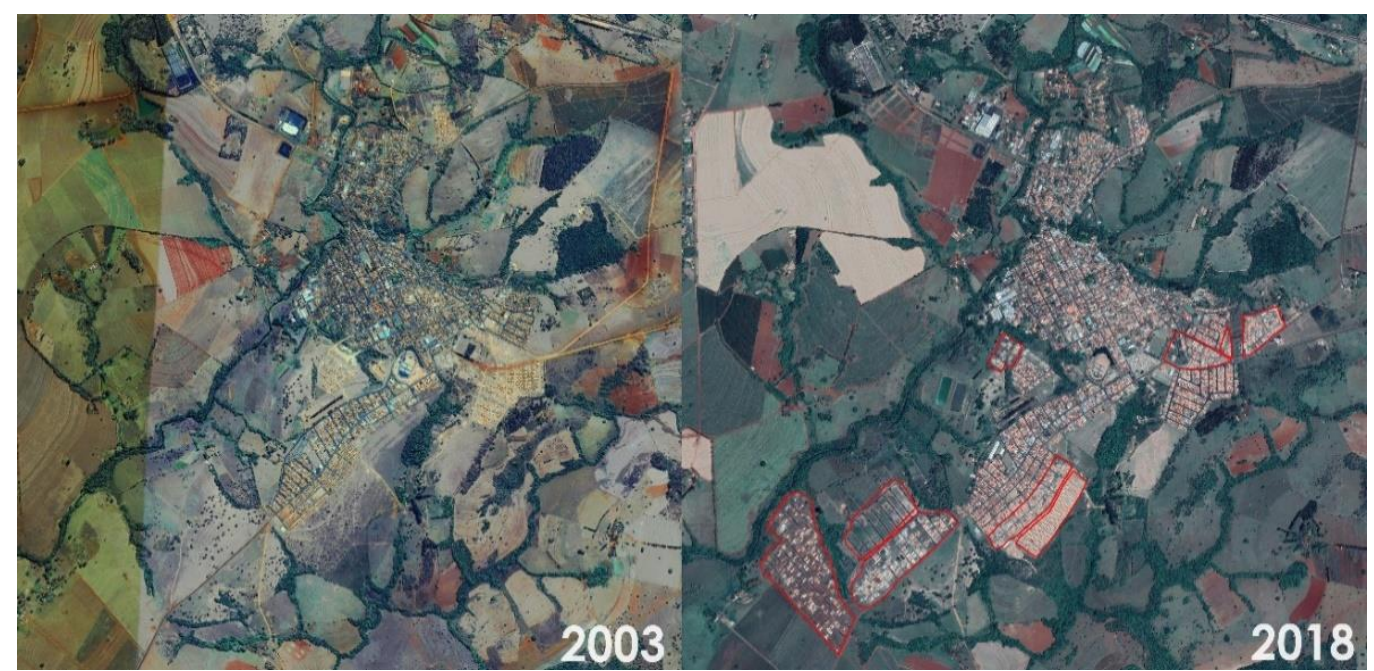

Figura 1 - Comparativo entre áreas incorporadas ao tecido urbano do município em um período de 15 anos.

Fonte: Google Earth Pro com modificações feitas pelo autor (2019)

\section{CONTEXTUALIZAÇÃO DO PARCELAMENTO DO SOLO CONSIDERANDO NORMAS LEGISLATIVAS E A QUESTÃO AMBIENTAL}

\section{1 Âmbito federal}

Os parcelamentos em área rurais, sejam para fins urbano ou agrícola, são regidos fundamentalmente pela instrução normativa 17-B do Instituto Nacional de Colonização e Reforma Agrária (INCRA) aliado aos descritivos da Lei N6.776, também conhecida como Lei Lehmann (DUTRA 2018). É válido destacar a que coordenadas o plano urbanístico se propõe na execução de desmembramento e loteamento, salientando formas de uso do solo. A partir do exposto, é possível identificar itens normativos obrigatórios quanto a aprovação de projetos urbanos de loteamento, em instâncias municipais, colocando em análise questões ambientais de implantação, estas, tão necessárias e indispensáveis quanto ao estabelecimento de itens reprobatórios, como equipamentos urbanos de escoamento das águas pluviais, iluminação pública, esgotamento sanitário, energia elétrica pública e domiciliar e vias de circulação.

Como estabelecido no Código Florestal ${ }^{1}$, é de responsabilidade do gestor administrativo vigente, a instauração de propostas públicas as quais priorizem a proteção de zonas de Área de Preservação Permanente, mananciais, redes hídricas e áreas verdes, bem como a fiscalização do correto manuseio dos mesmos. Não obstante ao código citado, é estabelecido na Constituição Federal, sob o Art. 225, a preservação e correta conversação de áreas verdes e recursos hídricos. Apesar de muito bem descritos em esfera legislativa, muitos pontos abordados nas normativas inseridas em texto, não se adequam a proposta projetual urbana então vigente na cidade analisada.

\section{2 Âmbito municipal}

A gama de explícitos em cunho legislativo é extensa e abrange muitos setores. No caso de Patrocínio Paulista, os decretos e leis ordinárias, são 
complementares a Legislação Federal, a então normativa regente em vigor para execução do uso do solo. Sob a Lei N825/77, estabelece-se a Lei Orgânica, na qual são citados atributos obrigatórios a regularização de parcelamento de lotes. No viés, a parcela referente à questão ambiental é mínima, atribuindo obrigatoriedade de execução de canteiros viários, por exemplo, mas desconsiderando a preservação do ambiente natural em áreas rurais.

Analisando o sistema legislativo, é possível identificar alguns dos pontos considerados na implementação de lotes, como:

- Obrigatoriedade da doação de espaços para equipamentos públicos;

- Dimensões mínimas de lotes estabelecidas por lei;

- Tratamento regulamentador para escoamento de água pluvial, esgotamento e energia elétrica.

Pontos estes que, embora sejam positivos no plano de projeto, se apartam das questões ambientais. A seguir, são listados itens recorrentes na análise de loteamentos recentes que não se adequam no sistema de lotes do município (ver Quadro 1). Itens, esses, que, além de desconsiderar a Lei №6.766, ferem a preservação do meio ambiente já degradado e a preservação da paisagem, atentando a qualidade ambiental da cidade e de seus moradores.

Quadro 1 - Itens listados nas Leis 12.615 e 6.766 que não são aplicados em
Patrocínio Paulista

Fonte: Autores.

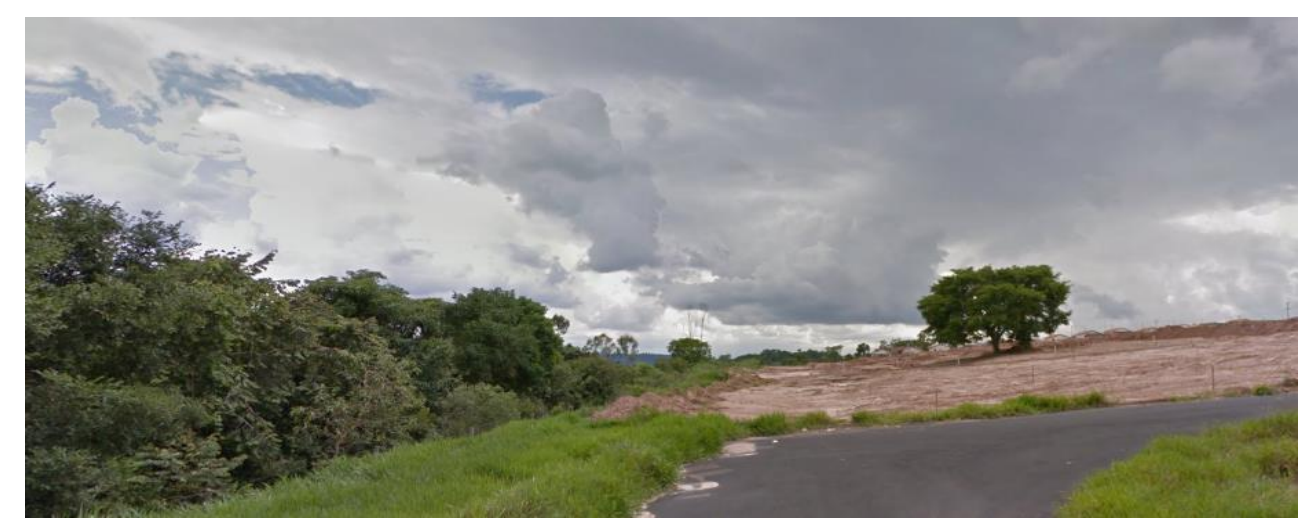

Figura 2 - Construção de loteamento próximo a mata ciliar. Fonte: Autores (2019). 


\section{PLANEJAMENTO E GESTÃO}

Sobre o exposto, fica evidente a necessidade de modificação das diretrizes legislativas e judiciárias vigentes em plano municipal, se considerado o enfoque central da causa ambiental. Entre estas podemos citar: a obrigatoriedade de doação de áreas públicas estabelecidos em quantitativos de construção findando preservação de área verde; o comprometimento da empresa responsável pela contratação de execução de loteamento urbano com a questão ambiental estabelecendo práticas sustentáveis na elaboração do projeto; e por fim, a fiscalização preeminente a partir do órgão público da administração municipal em regime.

Compete ao poder administrativo municipal capacitar os eixos correspondentes ao correto manuseio das políticas públicas, direcionando, principalmente, o projeto urbano e construção de infraestrutura sustentável ao indivíduo que habita àquele local. Nesse sentido, compete ao poder público direcionar as problemáticas urbanas e ambientais a setores especializados do Governo do Estado de São Paulo, tais como o SEQUA (Sistema estadual de administração da qualidade ambiental, proteção, controle e desenvolvimento do meio ambiente e uso adequado dos recursos naturais); SMA (Secretaria do Meio Ambiente); CETESB (Companhia Ambiental do Estado de São Paulo); e outros.

\section{DESENVOLVIMENTO URBANO SUSTENTÁVEL: PARA QUEM?}

Correlacionado ao que foi apresentado, é importante frisar a necessidade de inclusão a práticas sustentáveis e preservação ambiental no projeto urbanístico, enfaticamente, frente aos impactos que a degradação ambiental traz ao espaço urbano. Em primeiro lugar, é necessário identificar a quem o projeto urbano se destina: à cidade ou às pessoas que ali irão habitar? Compreendendo que a priorização a vida habitante é elemento primordial na elaboração de projetos arquitetônicos e urbanísticos, fica evidente a adoção dos edifícios ao terceiro plano, sendo o segundo, destinado aos espaços urbanos (GEHL 2013). Dessa forma, loteamento de áreas urbanas devem ser projetados de acordo com a demanda populacional pré-estabelecida, somada ao estudo de quem serão seus residentes, se tratando de loteamento residencial. Elementos que garantam qualidade de vida aos moradores daquele espaço a ser interferido, devem ser postos em primeiro plano. Por esse olhar, entende-se os planos ambientais (considerando os recursos hídricos, vegetação existente e morfologia do solo) ao parcelamento construído, adequando a massificação em concreto sob aquele solo a ser modificado.

Práticas sustentáveis, e de caráter preservacionista, são os pilares de boas práticas ao tratar dos pontos que confirmam qualidade de vida em um ambiente urbano. A adoção de medidas que potencializem o contingente arbóreo e vegetal nativos é imediata. É preciso reestruturar lotes já estabelecidos de forma que seja respeitada a distância mínima à APPs e mananciais, findando otimizar a qualidade vegetativa daquele local. Ainda, o caráter obrigatório da preservação ambiental deve ser aliado às questões jurídicas municipais, de forma a ser aplicada e fiscalizada. É fato que o adensamento verde em elevado índice agrega qualidade atmosférica e climática, além de desenvolver satisfação populacional se posto em 
consideração os equipamentos de lazer ao ar livre. Os pontos elencados se ajustam na correta, e indicativa, formatação dos loteamentos desejados.

\section{CONSIDERAÇÕES FINAIS}

A partir da abordagem articulada em texto, é válido ressaltar a compreensão do projeto em adequação a proposta habitacional, referenciando-se a quem irá abrigar, de forma vinculada a qualidade ambiental proporcionada. A preservação de áreas verdes e de recursos hídricos, se torna necessária ao ajuste de uma boa qualidade de vida observada na porção populacional habitante daquele local, visto que a degradação ambiental gera impactos negativos em diversos âmbitos. Buscando um resultado satisfatório em parcelamento à qualidade de vida do morador do loteamento a ser construído, é reforçada a tese de projeto conjuntural a ética sustentável, promovendo a preservação ambiental, a partir de indicadores de qualidade, findando a contenção de impactos negativos àquela população.

A correlação entre as camadas constituintes do resultado em ambiente construído deve ser analisada, de forma individual, para, por fim, apresentar um agregado completo e promover fluidez frente ao processo de urbanização. Dessa forma, se torna evidente a adoção imediata de integração ambiental e ambiente construído, mediada pela eficiência no uso de recursos naturais, adequando-os à necessidade de expansão urbana de forma a reduzir os impactos ambientais, degradando em menor ou nenhuma escala. Compreendendo a qualidade de vida social como intrínseca a qualidade ambiental, se torna fundamental a adoção de acordos locais que viabilizem a correta aplicação das diretrizes legislativas no plano expansivo de lotes.

\section{AGRADECIMENTOS}

Os autores do presente estudo, expõe agradecimentos diretos à Prefeitura Municipal de Patrocínio Paulista, pela oportunidade concedida ao ceder espaço para realização de estágio complementar acadêmico.

\section{REFERÊNCIAS}

FÉLIX, S. R. Patrocínio Paulista: 127 anos de história. 1 ed. São Paulo: Noovha América, 2012.

BRASIL. Lei $\mathbf{n} .^{\circ}$ 6.766, 19 de dezembro de 1979. Dispõe sobre o Parcelamento do Solo Urbano e dá outras Providências. Disponível em:

<http://www.planalto.gov.br/ccivil_03/LEIS/L6766.htm>. Acesso em: 08 fev. 2019.

IBGE - Instituto Brasileiro de Geografia e Estatística. Pesquisa Nacional por Amostra de Domicílios: síntese de indicadores 2010. Rio de Janeiro, 1998.

Prefeitura Municipal de Patrocínio Paulista. Câmara Municipal de Patrocínio Paulista. Legislação Municipal. Disponível em:

<http://camarapp.sp.gov.br/legislacao/legislacao-municipal>. Acesso em: 10 fev. 2019. 
GEHL, J. Cidade Para Pessoas/tradução Anita Di Marco. 2 ed. São Paulo: Perspectiva, 2013.

DUTRA, F. Plano Diretor e a Proteção do Meio Ambiente. TJRJ - Poder Judiciário do Estado do Rio de Janeiro. Rio de Janeiro. Disponível em:

<http://www.tjrj.jus.br/c/document_library/get_file? uvid=92cf023c-9a8a-4f4a923d-0df932340elf\&groupld=10136>. Acesso em: 12 fev. 2019. 